Jurnal Laut Khatulistiwa, Vol. 3 No. 3 (Oktober, 2020), Hal. 91-96.

\title{
Kepadatan dan Pola Distribusi Kima (Tridacna crocea) di Perairan Pulau Kabung Kalimantan Barat
}

\section{Density and Distribution Patterns of Clams (Tridacna crocea) in the Waters of Kabung Island West Borneo}

\author{
Eka Oktapyani ${ }^{1}$, Nora Idiawati ${ }^{1}$, Syarif Irwan Nurdiansyah ${ }^{1}$ \\ ${ }^{1}$ Laboratorium Ilmu Kelautan, FMIPA Universitas Tanjungpura, Pontianak, Indonesia \\ ${ }^{*}$ E-mail : pras.kelautan@gmail.com \\ Received : 3 April 2020; Accepted : 24 Mei 2020 \\ Published : 30 Juni 2020 (C) Author(s) 2020. This article is open access
}

\begin{abstract}
Research about the density and distribution patterns of clams in the Kabung island waters, West Borneo has been done. Determination of the location of observation is done by using a purposive sampling method that consists of two stations, i.e. zone near settlement along with ship acitivies and zone without settlement and ship acitivities. Clam sampling using the belt transect method. The result of this research have found 1 species, namely Tridacna crocea. The highest density of T. crocea was occured at station I $\left(0,078 \mathrm{ind} / \mathrm{m}^{2}\right)$, while the lowest density had been found at station II $\left(0,033 \mathrm{ind} / \mathrm{m}^{2}\right)$. Based on index of Morisita, distribution pattern of T. crocea which has been recorded Kabung Island can be categorized as clustered based Ip value of 0,5144 $($ Ip $>0)$.
\end{abstract}

Keywords : Clam, Density, Distribution Patterns, West Borneo

\begin{abstract}
Abstrak
Penelitian kepadatan dan pola distribusi kima di Perairan Pulau Kabung Kalimantan Barat telah dilakukan. Penentuan titik lokasi pengamatan dilakukan dengan menggunakan metode purposive sampling yang terdiri dari dua stasiun yaitu zona lokasi pemukiman dan aktivitas keluar masuk kapal dan zona lokasi tanpa pemukiman dan non-aktivitas keluar masuk kapal. Pengambilan sampel kima menggunakan metode belt transek. Hasil penelitian diperoleh 1 spesies yaitu Tridacna crocea. Kepadatan tertinggi diperoleh $T$. crocea pada stasiun I yaitu 0,078 ind $/ \mathrm{m}^{2}$, sedangkan nilai terendah diperoleh pada stasiun II yaitu 0,033 ind $/ \mathrm{m}^{2}$. Berdasarkan Indeks Morisita, kima $T$. crocea diperoleh pola distribusi mengelompok dengan nilai Ip sebesar 0,5144 (Ip > 0).
\end{abstract}

Kata kunci : Kima, Pola Distribusi, Kepadatan, Kalimantan barat

\section{Pendahuluan}

Perairan Pulau Kabung memiliki potensi sumberdaya laut dengan keanekaragaman ekosistem yang tinggi. Kondisi suatu ekosistem mempengaruhi biota yang hidup di dalamnya salah satunya kima (kerang raksasa). Kerang kima (Tridacnidae) merupakan hewan bertubuh lunak bercangkang termasuk dalam Kelas Bivalvia yang memiliki nilai ekonomi tinggi salah satunya cangkang kima (Calumpong, 1992). Cangkang kima dapat dijadikan sebagai bahan dekorasi selain itu kima sering dimanfaatkan oleh masyarakat sebagai makanan dengan jumlah pengambilan yang cukup banyak sehingga membuat CITES (Convention on International Trade in Endangered Species) menjadikan kima salah satu hewan yang dilindungi. Ambariyanto (2000) menyatakan bahwa upaya dalam perlindungan kima di Indonesia belum berjalan efektif akibat dari kurangnya pengetahuan, informasi, serta lemahnya pengawasan dan penegakan hukum terkait status kima di perairan.

Hasil penelitian mengenai kepadatan kima pada masing-masing daerah di Indonesia menunjukkan bahwa kepadatan kima yang 
Jurnal Laut Khatulistiwa, Vol. 3. No. 3 (Oktober, 2020), Hal. 91-96.

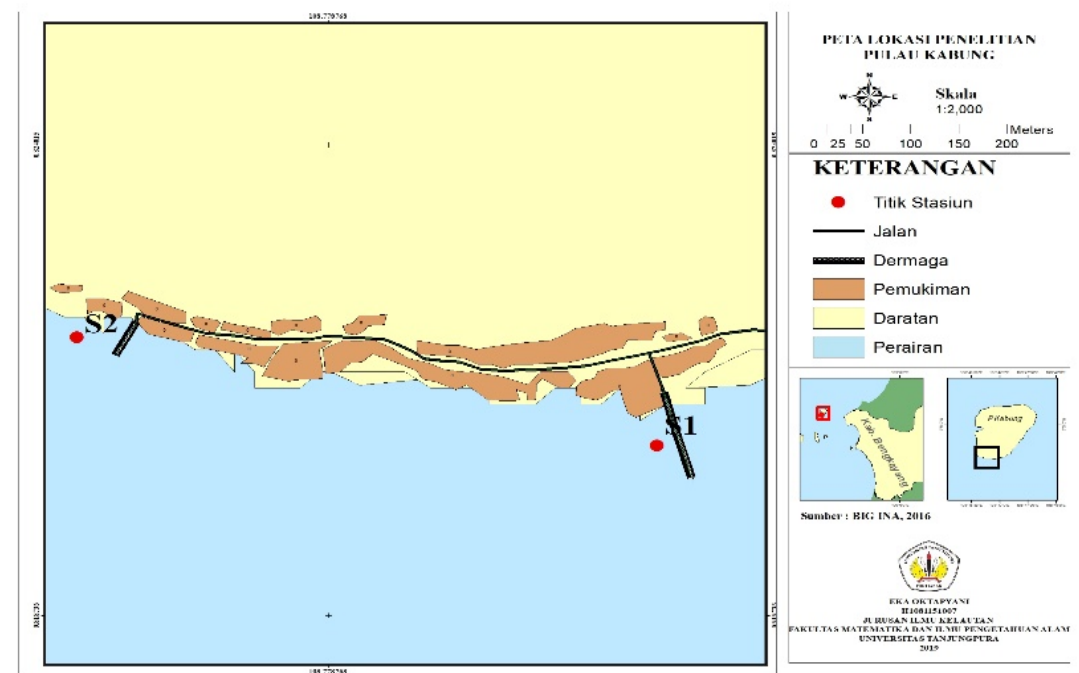

Gambar 1. Peta lokasi penelitian di Perairan Pulau Kabung Kalimantan Barat

dilakukan Niwasdita (2019) di Perairan Laut Desa Sepempang $\left(0,2\right.$ ind $\left./ \mathrm{m}^{2}\right)$, Ode (2017) di Perairan Teluk Nitanghahai $\left(0,048\right.$ ind $\left./ \mathrm{m}^{2}\right)$ dan (Arbi, 2010) di Perairan Sulawesi Utara ditemukan kepadatan kima sebesar $(0,032$ ind $\left./ \mathrm{m}^{2}\right)$. Mengingat adanya pengambilan kima secara terus menerus mengakibatkan menurunnya populasi kima di habitatnya, sehingga diperlukan data dan informasi sebagai bahan acuan dalam mengambil langkah atau kebijakan mengenai pengelolaan kima secara berkelanjutan. Hal tersebut menjadikan penelitian kima di Perairan Pulau Kabung Kalimantan Barat sebagai bagian penting untuk dilakukan dengan tujuan mengetahui kepadatan dan pola distribusi kima.

\section{Metodologi Penelitian}

\subsection{Waktu dan Tempat Penelitian}

Metode Pengambilan data dilakukan pada bulan Oktober 2019, meliputi pengambilan data lapangan, dan pengolahan data. Lokasi penelitian berada di kawasan pulau Kabung, kabupaten bengkayang Provinsi Kalimantan Barat. Pengambilan sampel kima dibagi menjadi 2 stasiun dengan penentuan titik lokasi pengamatan.

\subsection{Analisis Data}

Pada penelitian ini menggunakan metode purposive sampling berdasarkan rona lingkungan.
Pengamatan di lapangan dilakukan untuk mendapatkan data kima. Pengambilan sampel kima menggunakan belt transek yang dibuat sebanyak 1 transek pada setiap stasiun. Panjang setiap transek dibuat dengan ukuran $50 \mathrm{~m}$ sejajar garis pantai. Jumlah plot yang dibuat pada setiap transek sebanyak 5 buah (10 x $20 \mathrm{~m})$. Data kima yang diambil meliputi jenis pada luasan transek yang telah ditentukan dan tipe substrat yang dijadikan tempat hidup kima. Kemudian dilakukan pengukuran parameter fisika kimia yang diukur meliputi suhu, $\mathrm{pH}$, Dissolved Oxygen, salinitas, kedalaman dan kecepatan arus. Hasil pengukuran parameter tersebut dijadikan sebagai data pendukung penelitian. Hasil pengukuran parameter tersebut dijadikan sebagai data pendukung penelitian.

Analisis data Kepadatan kima dihitung menggunakan rumus yang mengacu pada Odum (1993) sebagai berikut:

$$
D=\frac{n}{A}
$$

Pola distribusi kima dihitung dengan menggunakan Indeks Morisita (Id) dengan rumus sebagai berikut (Jongjitvimol et al., 2005).

$$
\mathrm{Id}=\frac{\left(\sum x^{2}-\sum x\right)}{\left(\sum x\right) x^{2}-\sum x}
$$

Indeks keseragaman: $\mathrm{Mu}=\frac{x^{2} \cdot 0.975-n+\sum x i}{\left(\sum x i\right)-1}$

Indeks pengelompokan $\mathrm{Mc}=\frac{\mathrm{x}^{3} 0,025-\mathrm{m}+\sum \mathrm{xi}}{([\mathrm{X} i-1)}$ 
Jurnal Laut Khatulistiwa, Vol. 3. No. 3 (Oktober, 2020), Hal. 91-96.

Standarisasi indeks morisita dihitung dengan salah satu rumus dibawah sebagai berikut:

$$
\begin{aligned}
& \text { Ip : } 0.5+0.5\left(\frac{I d-M c}{n-M c}\right) \\
& \text { Ip : } 0.5+0.5\left(\frac{I d-1}{M c-1}\right) \\
& \text { Ip : } 0.5+0.5\left(\frac{I d-1}{M u-1}\right) \\
& \text { Ip : } 0.5+0.5\left(\frac{I d-M u}{M u}\right)
\end{aligned}
$$

\section{Hasil dan Pembahasan}

\subsection{Komposisi Kima (Tridacna crocea)}

Berdasarkan hasil penelitian yang dilakukan di Perairan Pulau Kabung, ditemukan 1 spesies yaitu Tridacna crocea dengan jumlah 111 individu. T. crocea yang dijumpai memiliki panjang cangkang kurang dari $15 \mathrm{~cm}$ dan membenamkan seluruh cangkangnya pada substrat keras (Gambar 2). T. crocea di Perairan Pulau Kabung dapat ditemukan pada setiap stasiunnya karena hidup dengan cara membenamkan seluruh cangkangnya pada karang sehingga sulit untuk diambil. Arbi (2010) menyatakan bahwa tingginya jumlah individu jenis $T$. crocea disebabkan rendahnya tekanan eksploitasi dari manusia maupun pemangsa.

\subsection{Kepadatan Kima (Tridacna crocea)}

Jenis T. crocea memiliki jumlah kepadatan yang bervariasi di setiap stasiun (Gambar 3). Stasiun I diperoleh kepadatan tertinggi $(0,078$ ind $/ \mathrm{m}^{2}$ ), sedangkan terendah pada stasiun II $\left(0,033\right.$ ind $\left./ \mathrm{m}^{2}\right)$. Rendahnya nilai kepadatan pada stasiun II diduga kondisi substrat di dasar Perairan tersebut didominasi oleh pasir yang tidak sesuai bagi T. crocea. Kondisi tersebut berkaitan erat dengan tempat hidup kima yaitu substrat. Hasil pengamatan menunjukkan bahwa stasiun I didominasi oleh karang keras (Faviidae) sesuai dengan Pangabean (1991) dan Ardi (2010) yang menyatakan bahwa kima dengan jenis $T$. crocea hidup di karang Faviidae.

\subsection{Pola Distribusi}

Hasil analisis indeks Morisita T. crocea diperoleh nilai Ip sebesar 0,5144 dan memiliki pola distribusi mengelompok (Ip $>0$ ) (Gambar 4 ). Berdasarkan hasil penelitian sebelumnya, di Perairan Laut Desa Sepempang ditemukan jenis kima $T$. crocea dengan pola distribusi yang mengelompok (Niwasdita, 2019).

Odum (1993) menyatakan bahwa biota yang hidup secara mengelompok diduga disebabkan oleh sifat bergerombol dan adanya keragaman habitat sehingga menyebabkan pada suatu daerah yang banyak terdapat makanan terjadi pengelompokan. Beberapa penelitian yang telah dilakukan juga menunjukan bahwa $T$. crocea memiliki pola distribusi mengelompok di Perairan Laut Desa Sepempang (Niwasdita, 2019), di perairan Teluk Nitanghahai (Ode, 2017), di Perairan Pulau Berhala Kepulauan Anambas (Saputra, 2016), dan di Perairan Pulau Congkak Kepulauan Seribu (Rizkevina, 2014), yang disebabkan adanya penumpukan makanan pada lokasi tersebut. Pola distribusi mengelompok juga terjadi disebabkan oleh cara reproduksi. Reproduksi kima disebut simultan hermaphrodite.
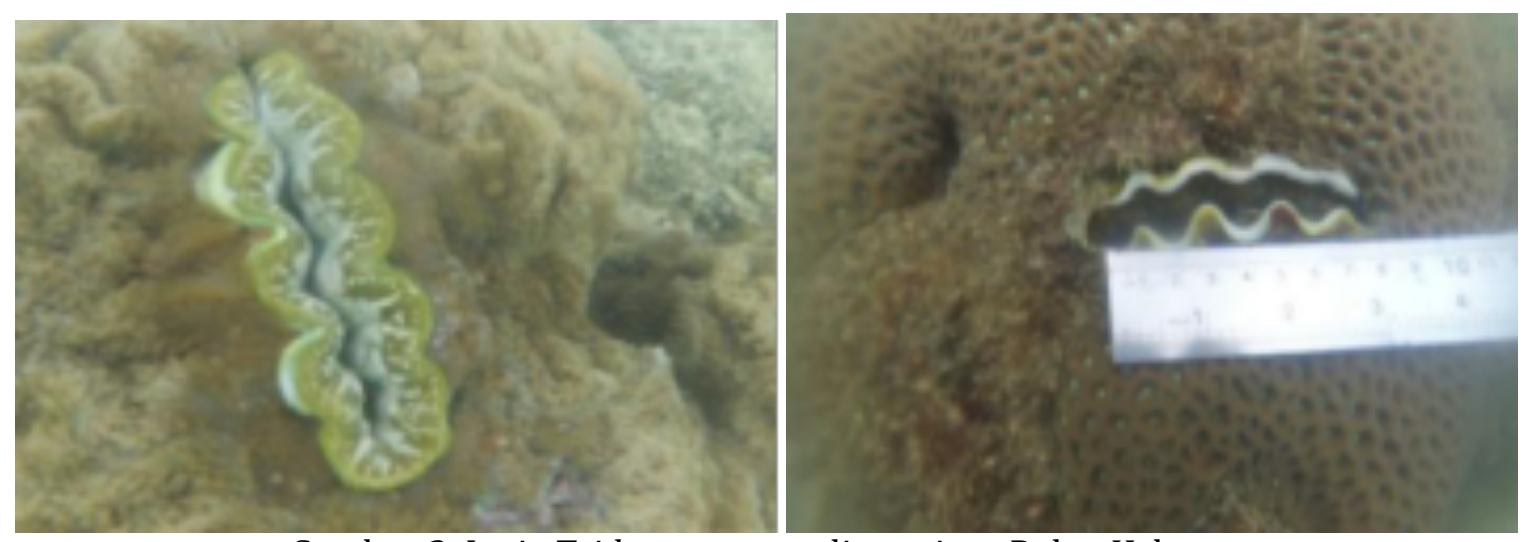

Gambar 2. Jenis Tridacna crocea di perairan Pulau Kabung 
Jurnal Laut Khatulistiwa, Vol. 3. No. 3 (Oktober, 2020), Hal. 91-96.
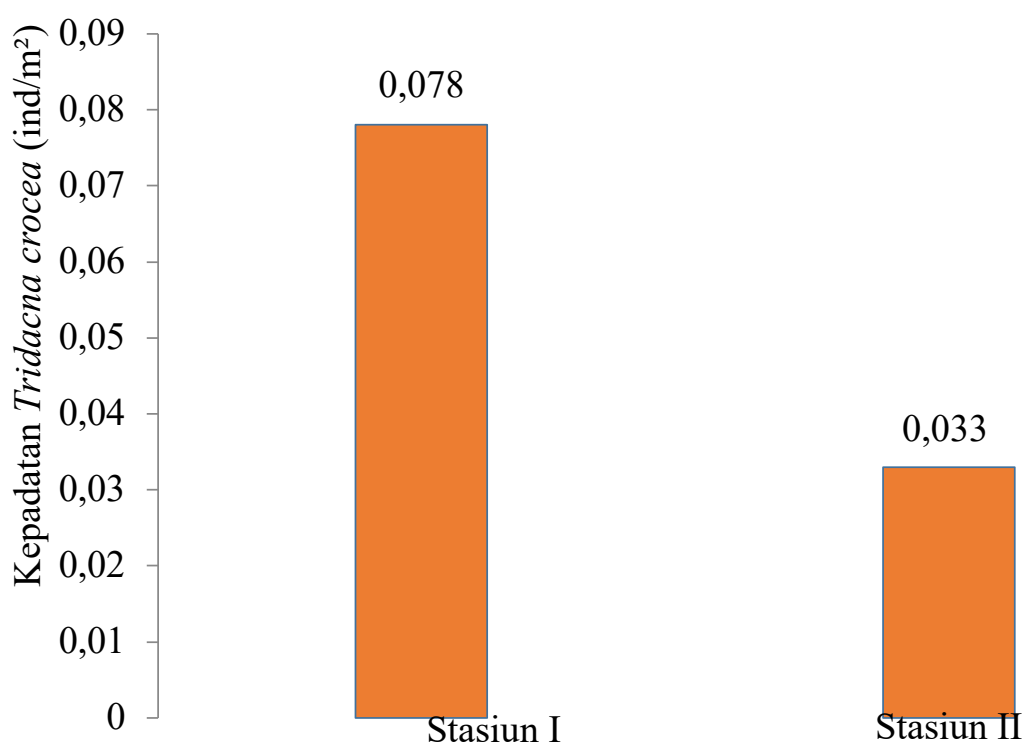

Gambar 3. Kepadatan jenis kima (Tridacna crocea) di Perairan Pulau Kabung

Cara reproduksi ini selalu didahului oleh keluarnya sperma lalu kemudian sel telur. Cara ini juga berpengaruh terhadap individu kima dewasa yang lain saat melakukan reproduksi, sel-sel telur yang terbawa oleh arus akan merangsang induk-induk kima dari jenis yang sama di sekitarnya untuk memijah (Cappenberg, 2007). Pemijahan merupakan bagian penting dalam reproduksi kima, dikatakan berhasil jika pada area terumbu karang hanya terdapat 1 atau 2 kima dewasa, maka demikian cara mengelompok memberikan peluang yang lebih besar terjadinya fertilisasi.

\subsection{Parameter Fisika Kimia}

Parameter fisika-kimia merupakan bagian penting bagi kehidupan kima. Susiana (2014) menyatakan bahwa adanya hubungan antara parameter fisika kimia terhadap kelimpahan kima, seperti kecepatan arus, suhu, DO, pH, salinitas dan kedalaman.

Berdasarkan hasil pengamatan kondisi Perairan Pulau Kabung masuk dalam kategori yang optimal untuk kehidupan kima (Tabel 1). Suhu di Perairan Pulau Kabung masih dalam kategori baik yaitu 26,93-31,46. Suhu yang optimal bagi pertumbuhan kima yaitu 28-31. Salinitas di Perairan Pulau Kabung menunjukan kategori yang baik bagi pertumbuhan kima yaitu 30,36-30,63 ppt. Salinitas yang baik bagi kehidupan kima yaitu 30-35 ppt (Litaay et al,. 2007). Nilai pH yang optimal bagi kehidupan kima yaitu 7-8,5 (Hamuna, 2018). Parameter pH di Perairan Pulau Kabung masuk dalam kategori yang masih dapat ditolerir kima $(8,61-8,78)$. Oksigen terlarut di Perairan Pulau Kabung menunjukkan dalam kategori baik untuk mendukung kehidupan kima $(9-10,5)$. Niartiningsih et al. (2008) menyatakan bahwa kima dapat hidup dengan kisaran nilai oksigen terlarut $(6,6-11,7 \mathrm{mg} / \mathrm{L})$. Kedalaman yang terukur di Perairan Pulau Kabung (0,7-1,8 m). Kecepatan arus di Perairan Pulau Kabung yaitu 0,03-0,08 m/s. Kecepatan arus tertinggi diperoleh pada stasiun I yaitu $0,08 \mathrm{~m} / \mathrm{s}$, hal ini dikarenakan pada saat pengambilan data terjadinya pasang surut air laut (pada siang hari) dan angin yang kuat. Kecepatan arus yang optimal bagi kehidupan kima yaitu 0,1-0,4 m/s (Litaay et al,. 2007). 
Jurnal Laut Khatulistiwa, Vol. 3. No. 3 (Oktober, 2020), Hal. 91-96.

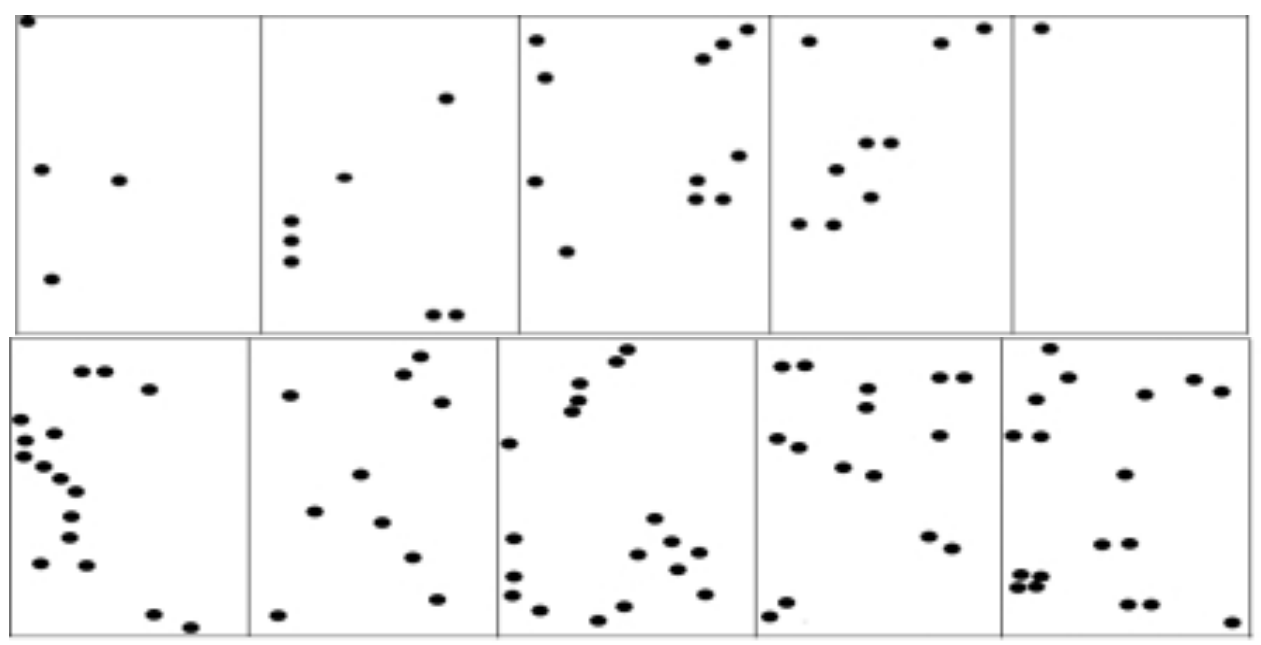

Gambar 4. Pola distribusi kima (Tridacna crocea) Stasiun I (atas) dan Stasiun II (bawah) di perairan Pulau Kabung.

Tabel 1. Parameter Fisika-Kimia di Perairan Pulau Kabung

\begin{tabular}{|c|c|c|c|c|}
\hline No & $\begin{array}{l}\text { Parameter } \\
\text { Lingkungan }\end{array}$ & Stasiun I & Stasiun II & Kisaran Optimal \\
\hline 1. & Suhu $\left({ }^{\circ} \mathrm{C}\right)$ & $26,93-30,53$ & $28,8-31,46$ & $28-31^{\circ} \mathrm{C}$ (Litaay et., al 2007) \\
\hline 2. & Salinitas (ppt) & $30,36-30,63$ & $30,53-31,1$ & 30-35 ppt (Litaay et., al 2007) \\
\hline 3. & $\mathrm{pH}$ & $8,67-8,78$ & $8,61-8,71$ & 7-8,5 (Hamuna, 2017) \\
\hline 4. & $\mathrm{DO}(\mathrm{mg} / \mathrm{L})$ & $7,4-9,8$ & $7,5-10,3$ & $\begin{array}{l}\text { 6,6-11,7 mg/L (Niartiningsih et., al } \\
2012 \text { ) }\end{array}$ \\
\hline 5. & Kedalaman (m) & $0,7-1,3$ & $1,2-1,8$ & 1-4 m (Niartiningsih et., al 2013) \\
\hline 6. & $\begin{array}{l}\text { Kecepatan arus } \\
(\mathrm{m} / \mathrm{s})\end{array}$ & $0,03-0,08$ & $0,05-0,07$ & 0,1-0,4 m/s (Litaay et., al 2007) \\
\hline
\end{tabular}

Berdasarkan hasil pengukuran kecepatan arus di stasiun I dan II masih dalam kategori lambat. Yusuf et al. (2012) menyatakan bahwa kecepatan arus dikategorikan kuat apabila kecepatan arus bernilai $0,5 \mathrm{~m} / \mathrm{s}$. Berdasarkan analisis regresi, parameter yang mempengaruhi kehidupan kima adalah kecepatan arus dan pada waktu pengambilan sampel menunjukkan pengaruh yang signifikan terhadap kepadatan kima yaitu semakin tinggi kecepatan arus menjadikan kepadatan kima semakin rendah.

\section{Kesimpulan}

Kepadatan kima di perairan Pulau Kabung Kalimantan Barat di semua stasiun hanya ditemukan 1 spesies yaitu Tridacna crocea. Kepadatan kima di stasiun I memiliki nilai
0,073 ind $/ \mathrm{m}^{2}$, sedangkan di stasiun II memiliki nilai 0,033 ind $/ \mathrm{m} 2$. Pola distribusi kima jenis $T$. crocea dikategorikan menggelompok dengan nilai Ip sebesar 0,5144 berdasarkan indeks morisita.

\section{Ucapan Terima Kasih}

Penulis mengucapkan terimakasih kepada orang tua, dosen pembimbing dan penguji skripsi, dan teman-teman seperjuangan atas bimbingan dan dukungannya selalu dalam penyelesaian penelitian ini.

\section{Daftar Pustaka}

Ambariyanto, S. Yusup, I. Ramli, S. Hadi. 2000. The Condition of Giant Clams Natural 
populatio in Indonesia. Paper dipresentasikan pada The 9 th International Coral Reef Symposium, 2327 Oktober 2000. Bali, Indonesia.

Arbi, U.Y. 2010. Kepadatan dan Kondisi Habitat Kerang Kima (Cardiidae: Tridacninae) di Beberapa Lokasi di Perairan Sulawesi Utara. Jurnal Bawal. 3:139-148.

Calumpong, H.P. 1992. The Giant Clam: An ocean culture manual, Australian Centre for International Agricultural Research, Canberra.

Cappenberg, H.A.W. 2007. Sebaran dan Kepadatan Kima (Tridacnidae) di Perairan Kepulauan Derawan Kalimantan Timur. Jurnal Fish. Sci. 9:220-225.

Hamuna, B. R.H.R., Tanjung, Suwitno. H.K. Maury, dan Alianto. 2018. Kajian Kualitas Air Laut dan Indeks Pencemaran Berdasarkan Parameter Fisika-Kimia Di Perairan Distrik Depapre Jayapura Jurnal Ilmu Lingkungan. 16:35-43.

Knop, D. 1996. Giant Clams, A Comprehensive Guide to the Identification and Care of Tridacnid Clams, DahneVerlag, Ettlingen, 251.

Kusmana, C., I. Setyobudiandi, S. Hariyadi, dan A. Sembiring. 2015. Sampling dan Analisis Bioekologi Sumber Daya Hayati Pesisr dan Laut. Edisi ke-1. IPB Press : Indonesia.

Litaay, M., R.B. Gobel, A. Abdullah, K. Alie, dan S. Lejab. 2007. Kulaitas Media Pemeliharaan Larva Lola Merah dan Kima Sisik Hasil Filtrasi Bertingkat di Hatchery. Jurnal Ilmu Kelautan. 12:2430.

Niartiningsih, A., S. Yusuf, dan M. A. Amran. 2013. Pemetaan Populasi Biota Langka Kima (Tridacnidae) dan Upaya Konservasi melalui Perbaikan Mutu Benih Untuk Restocking- Laporan Penelitian Strategis Nasional (Stranas), Dirjen Dikti.

Niwasdita, I.P. 2019. Kepadatan dan Pola Distribusi Kima (Tridacnidae) di
Perairan Laut Desa Sepempang Kecamatan Bunguran Timur Kabupaten Natuna. Skripsi. Pontianak : Universitas Tanjungpura.

Ode, I. 2017. Kepadatan dan Pola Distribusi Kerang Kima (Tridacnidae) di Perairan Teluk Nitanghahai Desa Morella Maluku Tengah. Jurnal Agrikan. 10:2.

Odum, E.P. 1993. Dasar-Dasar Ekologi. T. Samingan. (alih bahasa). Yogyakarta: Gadjah Mada University Press.

Panggabean, L.M.G. 1991. Rahasia Kehidupan Kima: II. Evolusi. Jurnal Oseana. 16:3544.

Rizkevina, Q. 2014. Keanekaragaman Jenis dan Distribusi Kerang Kima Family Tridacnidae (Kerang Kima) di Perairan Pulau Karang Congkak, Kepulauan Seribu. Skripsi. Jakarta : Universitas Islam Negeri Syarif Hidayatullah.

Salmin, 2005, Oksigen Terlarut (DO) dan Kebutuhan Oksigen Biologi (BOD) Sebagai Salah Satu Indikator Untuk Menentukan Kualitas Perairan, J. Oseana., 30:21-26.

Saputra, Adiska. 2016. Pola Sebaran Kima Di Perairan laut Pulau Berhala kecamatan Jemaja Kabupaten Kepulauan Anambas Propinsi Kepulauan Riau. Skripsi. Riau : Universitas Maritim Raja Ali Haji.

Widyasari, F., B.W. Santoso, A. Gulam, S.M. Didik, L. Nasrul, dan A. F. Reza. 2016. Pengujian Kualitas Air di Perairan Pantai Negeri Morella Sebagai Habitat Kima (Tridacna sp.). Jurnal Airaha. 5:109-1. 